\title{
Erratum to: Active thermal management of on-chip hot spots using EWOD-driven droplet microfluidics
}

\author{
J.-T. Cheng $\cdot$ C.-L. Chen
}

Published online: 29 September 2010

(C) Springer-Verlag 2010

\section{Erratum to: Exp Fluids}

\section{DOI 10.1007/s00348-010-0882-4}

In the original publication the Acknowledgments was incomplete. The full text of the Acknowledgments reads as follows:

This work was supported by Rockwell Automation, Inc. and NASA (Contract No. NNC09CA36C). The authors thank L. Lin, D. Taber and B. Wen for EWOD device fabrication, technical assistance, and helpful discussion.

The online version of the original article can be found under doi:10.1007/s00348-010-0882-4. 